\title{
Bacteria (K. Pneumonia)-mediated production of gold nanoparticles and their in vitro studies
}

\author{
M Amin Bhat ${ }^{*}$, Anima Nanda ${ }^{1}$ and B. K. Nayak ${ }^{2}$ \\ ${ }^{1}$ Department of Biomedical Engineering, Faculty of Bio. \& Chemical Engineering, \\ Sathyabama University, Rajiv Gandhi Salai, Chennai - 600119, India \\ ${ }^{2}$ Department of Botany, K. M. Centre for P. G. Studies (Autonomous), Lawspet, Pondicherry- \\ 605008, India \\ *Email:. aminbio3@gmail.com
}

Today Nanotechnology and nano-engineering has created one of the most dynamic science and technology domains to produce significant scientific and technological advances in various fields. It has a number of scopes, opportunities and potential applications in relation to living system. As human health and their comfort are concerned, nanotechnology has a potential impact on it and simultaneously public also demands a lot from the researchers. Nowadays research is going on to develop tools to refine their applications in medical and biological fields $[1,2]$. The products and processes based on nano-technological applications can help to improve the lives of those living in developing countries through a range of healthcare innovation $[2,3]$.

In present study, gold nanoparticles were biologically synthesized from clinical pathogen klebsiella pneumoniae bacteria to target the cancer cells and human pathogens. The media free bacterial biomass was treated with $\mathrm{HAuCl}_{4}$ at $1 \mathrm{MM}$ and was kept for incubation was diluted with $50 \mathrm{ml}$ of distilled water containing the culture pellet and placed in rotatory shaker at $150 \mathrm{rpm}$ till the color changed. The change in color from white to yellow after addition of $\mathrm{HAuCl}_{4}$ and the appearance of dark purple color after $48 \mathrm{hrs}$ confirms the reduction of gold chloride into gold nanoparticles Figure 1. The formation of nanoparticles was confirmed by UVvisible spectroscopy with the maximum absorbance at $534 \mathrm{~nm}$, characteristics of gold nanoparticles. Xray diffraction (XRD) and Field emission Scanning Electron Microscopy (FESEM) was used to determine the metallic character of AuNPs as well as the size and Morphology of nanoparticles which ranges in between 35-48nm Figure 2.
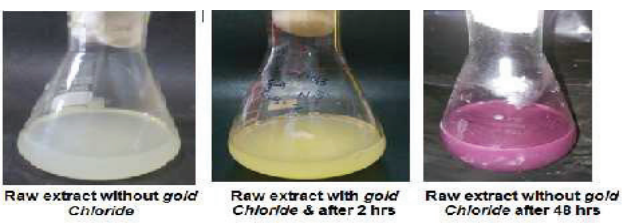

Figure 1: Biosynthesis of Gold Nanoparticles from $K$. pneumoniae after adding gold chloride
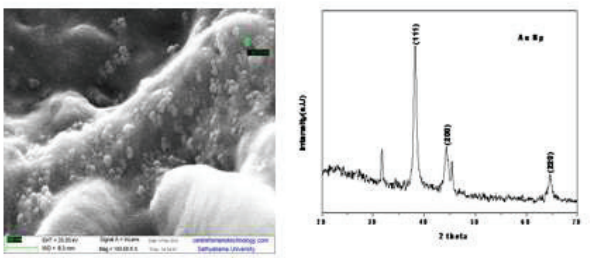

Figure 2: FESEM and XRD analysis of biologically synthesized Gold nanoparticles

The biologically engineered gold nanoparticles after characterization were checked for biomedical applications and showed toxicity to words HEp-2 cells and was found significant with its $\mathrm{IC}_{50}$ value at $62.5 \mu \mathrm{g} / \mathrm{ml}$ compared with normal Vero cells with $\mathrm{IC}_{50}>250 \mu \mathrm{g} / \mathrm{ml}$ Figure 3 . The anti-proliferative activity to words HEp-2 cells could be extended to anticancer studies after evaluating its toxicity in vivo. In addition gold nanoparticles also showed good antibacterial activity against selected human pathogens. Thus biologically synthesized nanoparticles could become simple and reliable source to solve important health challenges and cater to unmet medical needs in driving nanomedical research.

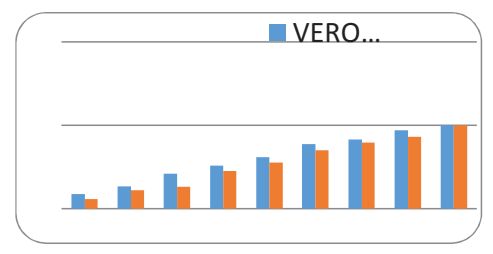

Figure 3: Graphical Representation of \% cell Viability between HEP-2 and Vero cell lines.

\section{References}

1. A. Binupriya, M. Sathishkumar, S. Yun. Colloid Surface B 79(2010):531-534.

2. M. A. Bhat, B. K. Nayak, A. Nanda. J Pure and App. Microb. 8(2014) 4201-4207.

3. C. Malarkodi, S. Rajeshkumar, M. Vanaja, K. Paulkumar,G. Gnanajobitha, G. Annadurai. J Nanostructure in Chem. 3(2013) 2. 